\title{
Drought resistance of two Douglas fir species (Pseudo- tsuga menziesii (Mirb.) Franco and Pseudotsuga macro- carpa (Torr.) Mayr.): relative importance of water use efficiency and root growth potential
}

\author{
G. Aussenac, P. Grieu and J.M. Guehl
}

Laboratoire de Bioclimatologie et Ecophysiologie Forestière, Station de Sylviculture et de Production, INRA Centre de Nancy, Champenoux, 54280 Seichamps, France

\section{Introduction}

In order to optimize the choice of species for reforestation in regions subjected to summer water shortage, it is important to determine which physiological components may be involved in their drought adaptation. Therefore, we have carried out this study aimed at comparing the ecophysiological behavior of 2 Douglas fir species: Pseudotsuga menziesii (Mirb.), originating from a relatively wet coastal zone (Ashford, WA, U.S.A., $300 \mathrm{~m}$ elevation) and Pseudotsuga macrocarpa (Torr.) Mayr., growing under drier conditions (CA, U.S.A., 1315 m elevation).

\section{Materials and Methods}

Carbon dioxide assimilation rate $(A)$, stomatal conductance $\left(g_{S}\right)$ and transpiration rate $(E)$ were measured on 2 yr old seedlings: 1) during a soil water depletion cycle (the water status of the plants was determined by predawn water potential measurements), while the leaf-to-air water vapor pressure difference $(\Delta W)$ was maintained at 4.6 $\mathrm{Pa} \cdot \mathrm{KPa}^{-1}$, and 2) in response to increasing $\Delta W$ in well-watered plants. The measurements were performed with an assimilation chamber in which air temperature, ambient $\mathrm{CO}_{2}$ concentration, photosynthetic photon flux density and water vapor pressure were controlled. Analyzing the data trough $A$ vs Intracellular $\mathrm{CO}_{2}$ molar fraction $\left(C_{j}\right)$ graphs, we could determine stomatal and mesophyll components of changes in $A$ (Prioul et al., 1984; Jones, 1985). The gas exchange response to $\Delta W$ was also examined with respect to the optimization theory of Cowan and Farquhar (1977).

In a second experiment (Grieu and Aussenac, 1988), non-destructive measurements of the number of growing roots and root elongation were made on 3 mo old seedlings of the 2 species grown in root boxes.

\section{Results}

Data of Fig. 1a show that the peak rates of $A$ were higher in $P$. menziesii than in $P$. macrocarpa. After an initial increase, mesophyll photosynthesis remained unchanged over a wide predawn water potential range in both species, while $g_{S}$ 


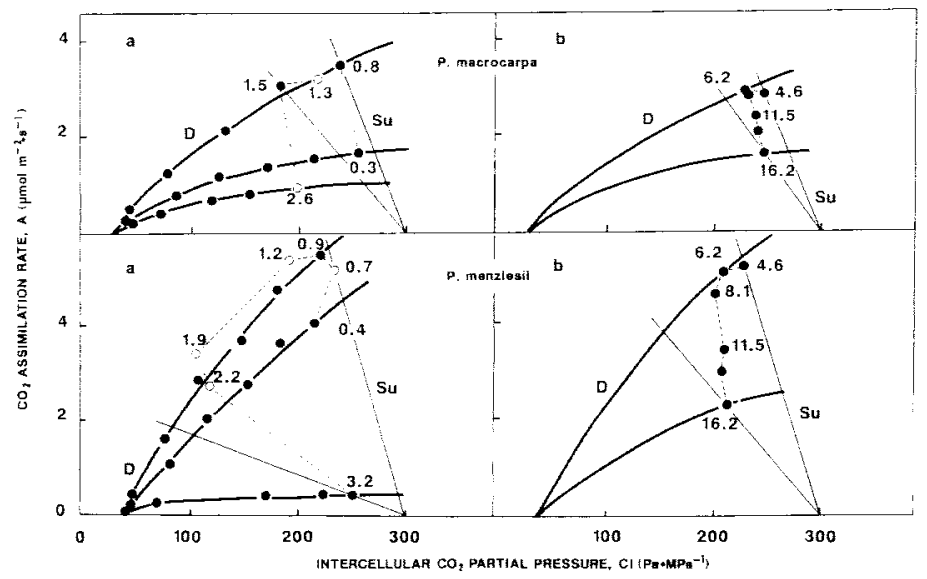

Fig. 1. Rate of $\mathrm{CO}_{2}$ assimilation (A) against interceliular $\mathrm{CO}_{2}$ molar fraction ( $C_{i}$ ). a. At different leaf predawn water potential levels reported on the figure (absolute values in $\mathrm{MPa}$ ) at a $\Delta W=4.6 \mathrm{~Pa} \cdot \mathrm{KPa}^{-1}$. b. At different $\Delta W$ levels reported on the figure ( $\left.\mathrm{Pa} \cdot \mathrm{KPa}^{-1}\right)$ in well-watered plants. $D$ : photosynthetic demand functions for $\mathrm{CO}_{2}, \mathrm{Su}: \mathrm{CO}_{2}$ supply functions at ambient $\mathrm{CO}_{2}$ molar fraction $C_{a}=300 \mathrm{~Pa} \mathrm{MPa}^{-1}$. D has been established either experimentally by varying $C_{a}$ or extrapolated ( $\Delta W$ responses) from experimental data not reported here. For a given species and experiment, only the 2 extreme $S u$ have been reported. In both experiments, the points obtained at $C_{a}=300$ $\mathrm{Pa} \cdot \mathrm{MPa}^{-1}$ have been joined (dashed line). (Adapted from Grieu et al., 1988.)

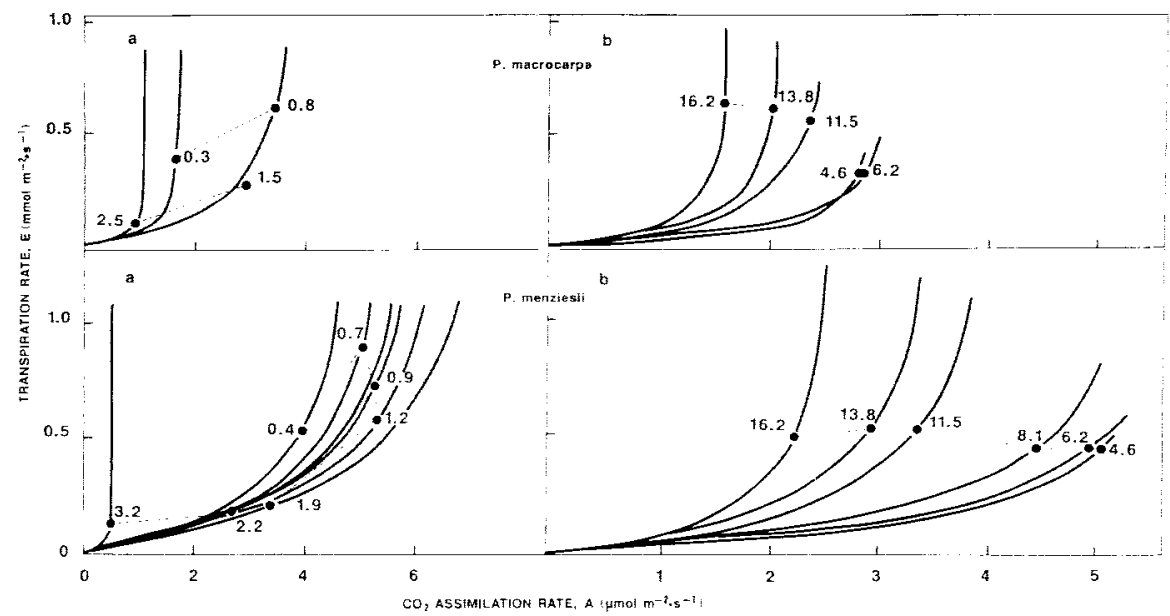

Fig. 2. Transpiration functions $E(A)$ a. At different leaf predawn water potential levels and $\Delta W=4.6 \mathrm{~Pa} \cdot \mathrm{MPa}-1$. b. At different $\Delta W\left(\mathrm{~Pa}_{\mathrm{K}} \mathrm{Pa}^{-1}\right)$ levels in well-watered plants. The different water potential and $\Delta W$ values are directly reported in the figure. For a given water potential or $\Delta W, E(A)$ is the function that would be obtained if only stomatal conductance were changed. The slope of $E(A)$ at the actual experimental point is equal to the marginal unit water cost of $\mathrm{CO}_{2}$ assimilation $(\partial E / \partial A)$. Optimal stomatal functioning would imply $\partial E / \partial A$ to be constant with $\Delta W$. (Adapted from Grieu et al., 1988.) 
was reduced. At higher soil drought, a dramatic decline of mesophyll photosynthesis was noted starting from $-1.5 \mathrm{MPa}$ in $P$. macrocarpa and $-1.9 \mathrm{MPa}$ in $P$. menziesii.

In both species, stomatal conductance and especially mesophyll photosynthesis were dramatically decreased, as $\Delta W$ was increased (Fig. 1b).

$P$. macrocarpa had the highest and the most unstable - and thus non-optimal - values of $\partial E / \partial A$ in response to increasing $\Delta W$ (Fig. 2a). $P$. macrocarpaalso had the highest $\partial E / \partial A$ at high water potential (Fig. 2b).

Growth of the pre-existent roots was more important in $P$. macrocarpa than in $P$. menziesii and growth of the new roots was similar in both species (Fig. 3). Furthermore, P. macrocarpa explored the deep soil layers more quickly tha $P$. menziesii (Fig. 4.).

\section{Conclusions}

Unexpectedly, in the present comparative study the results show that the droughtresistant $P$. macrocarpa had the lowest

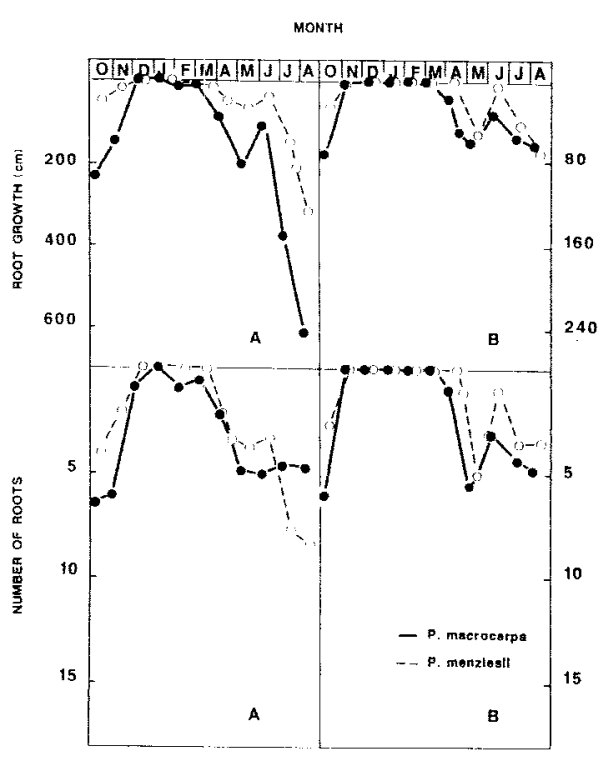

Fig. 3. Monthly time-course of number of growing roots and of root elongation in the 2 species studied. A. Existing roots. B. New roots. (Adapted from Grieu and Aussenac, 1988.)

gas exchange rates and exhibited the least conservative water economy.

The high drought adaptation of $P$. macrocarpa seems to be due mainly to

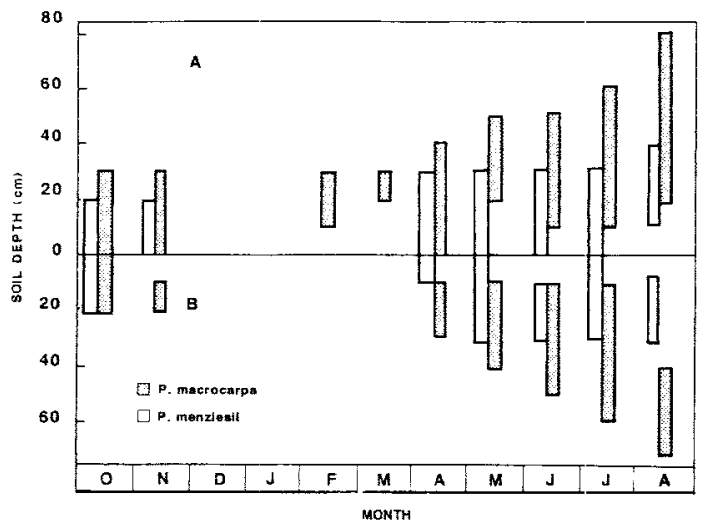

Fig. 4. Soil depth at which monthly root growth of the 2 species studied was observed. A. Growth of the preexisting roots. B. Growth of the new roots. (Adapted from Grieu and Aussenac, 1988.) 
efficient root growth and soil exploration abilities, whereas, surprisingly, no adaptation features seem to have developed at the leaf level.

\section{References}

Cowan I.R. \& Farquhar G.D. (1977) Stomatal function in relation to leaf metabolism and environment. Symp. Soc. Exp. Biol. 31, 471-505

Grieu P. \& Aussenac G. (1988) Croissance et développement du système racinaire de semis de trois espèces de conifères: Pseudotsuga menziesii, Pseudotsuga macrocarpa et Cedrus atlantica. Ann. Sci. For. 45, 117-124

Grieu P., Guehl J.M. \& Aussenac G. (1988) The effects of soil and atmospheric drought on photosynthesis and stomatal control of gas exchange in three coniferous species. Physiol. Plant. 73, 97-104

Jones H.G. (1985) Partitioning stomatal and non-stomatal limitations to photosynthesis. Plant Cell Environ. 8, 95-104

Prioul J.L., Cornic G. \& Jones H.G. (1984) Discussion of stomatal and non-stomatal components in leaf photosynthesis decline under stress conditions. In: Advances in Photosynthesis Research (Sybesma C., ed.), vol. IV, Martinus Nijhoff/W. Junk, The Hague, pp. 375-378 